\title{
INSTALLATION OF SUBMARINE CABLES IN THE OFFSHORE WIND INDUSTRY AND THEIR IMPACT ON THE MARINE ENVIRONMENT
}

\author{
Valeriu-Florian VASILESCU ${ }^{1}$, Dumitru DINU ${ }^{2}$ \\ ${ }^{1}$ Constanta Maritime University, Doctoral School of Mechanical Engineering and Mechatronic, 104 Mircea cel Batran \\ Street, 900663, Constanta, Romania, e-mail vasilescuvaleriu75@gmail.com \\ ${ }^{2}$ Constanta Maritime University, Doctoral School of Mechanical Engineering and Mechatronic, 104 Mircea cel Batran \\ Street, 900663, Constanta, Romania, e-mail dumitru.dinu@gmail.com
}

\begin{abstract}
This article presents the main methods of installing submarine cables used in the offshore wind industry and the impact they have on the marine environment.

From this article, the reader will be able to understand the basic principles that are taken into account from the design phase of a submarine cable, principles that seek to streamline their installation, operation and maintenance and their impact on the marine environment. Given the scale of the development of the wind industry, especially offshore, the length of submarine cables that provide energy transport from the wind farm to shore consumers is also constantly growing. The construction and operation of offshore wind energy systems has been and continues to be regarded with scepticism by environmental activists. Despite the undeniable benefits of this renewable energy source, the impact on the marine environment must also be taken into consideration.

We studied the most efficient methods of installing submarine cables in the offshore wind industry - study which also includes analysing the behaviour of submarine cables and analysing ships' movement during cable transport and installation.

This article is only part of a major research on the installation of submarine cables in the offshore wind industry.

In terms of the frequency and relatively short duration of submarine cable installation operations, on a small strip of up to $8 \mathrm{~m}$, the disturbances and impact caused by these operations are considered minor and are preferred compared to bottom trawling operations and dredging, which are repetitive and more extensive. A single impact, such as cable burial operations, is preferred to continuous, multiple or recurrent impacts. [1]
\end{abstract}

Key words: wind energy, environment, technologies, analysis, efficiency, marine, cable layer.

\section{INTRODUCTION}

A 2015 Joint Research Center (JRC) report "HVDC Submarine Power Cables in the Word" mentioned that there are almost $8,000 \mathrm{~km}$ of highvoltage, direct current (HVDC) submarine electrical cables in the world. However, considering the current pace of offshore wind farms construction, submarine cables have become a ubiquitous element in electricity transmission.

Over $70 \%$ of the world's HVDC submarine cables (both in terms of number and length) are located in the seas adjacent to Europe (Fig. 1).

The first commercial HVDC submarine cable was installed in 1954 in Sweden by ABB Ltd., connecting the island of Gotland and the mainland. It had a length of 90 $\mathrm{km}$, a voltage of $100 \mathrm{kV}$ and a capacity of $20 \mathrm{MW}$. Since then, the technology has evolved towards a higher transport capacity and voltages.

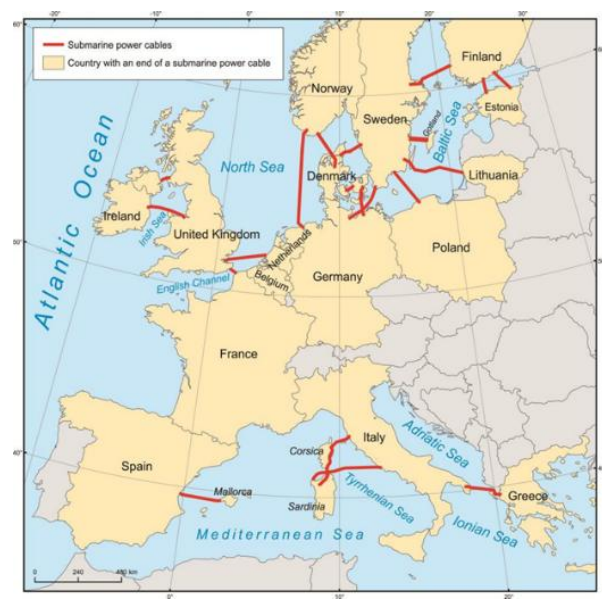

Figure 1 Submarine power cables in Europe [2] 


\section{DETERMINANTS IN THE MANUFACTURE AND INSTALLATION OF SUBMARINE CABLES}

\subsection{Geological study and survey of the cable's installation route}

A mandatory geological study of the cable route must be carried out before installing the submarine cable. This study should provide a complete and complex picture of the seabed in terms of bathymetry, depth gradient, nature of the seabed, environmental conditions. All these investigations are performed and evaluated by geophysicists, geologists, oceanographers using dedicated equipment. An incorrect assessment of these conditions would lead to improper cable design and therefore to malfunction or additional maintenance costs.

\subsection{Geological structure}

Knowing the nature of the seabed is of critical importance. Placing submarine cables in stable environments will extend their life and guarantee an easier operation. The nature of the seabed is very diverse due to its varied geology and the processes that affect it.

Most of the seabed is covered by a thick layer of sediment that averages $450 \mathrm{~m}$ (Fig. 2). This layer can be thinner on the ridges in the middle of the ocean, where the structures, formed by hard rock and sometimes even volcanic lava flows, stand out.

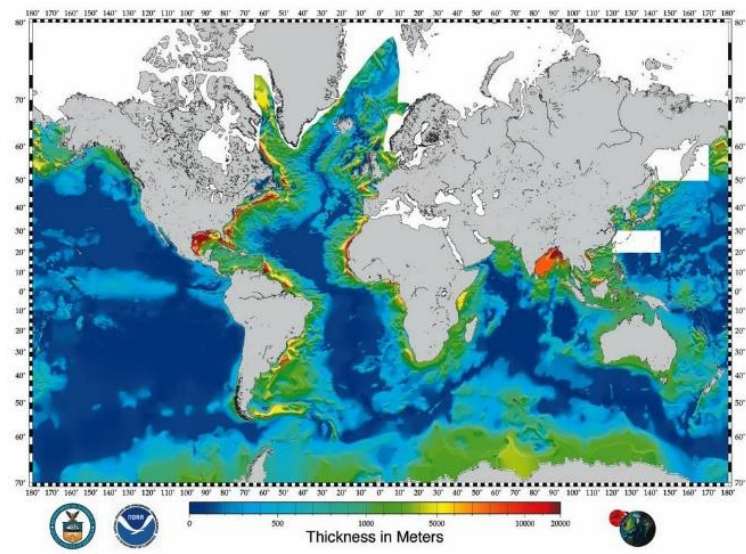

Figure 2 Total sediment thickness of the world's oceans and marginal seas [3]

Although the predominant process below the water surface is sedimentation, the movement of water can move finer particles, especially in coastal areas, causing changes in bathymetry on the seabed. In soft sediment (clay, mud, earth, sand), the easiest solution is to place the cable in a dug ditch. However, this also means that the cable can be easily removed or moved by waves and currents, which can damage it. This risk decreases with increasing depth, where the action of waves and sea currents decreases or becomes negligible. Harder sediments, such as gravel, provide better protection because they are heavier and less prone to movement, but harder to dig and therefore lead to higher costs.

\subsection{Water depth and subsea bed topography}

When choosing the routes for installing the cables, try to avoid deep trenches or steep slopes, while maintaining the shortest possible path. Because most submarine electrical cables installed so far cross shallow, flat-bottomed seas covered with thick Quaternary sediments (Baltic Sea, North Sea, Irish Sea, English Channel, Strait between Japan, Philippines, USA, Canada, Australia, New Zealand) the depth of the water and the slope were not a major concern. The depth threshold of $1000 \mathrm{~m}$ was exceeded only in the Mediterranean Sea.

In water environments, special attention must be paid to the hydrostatic pressure exerted by the water column, which could become an important factor both in the design and choice of materials used and in the methods of cable installation or repair. The pressure increases constantly with depth, with about one atmosphere (1 atm) every $10 \mathrm{~m}$.

The submarine cables installed so far cross the continental seas. The continental shelf is characterized by shallow waters (up to $200 \mathrm{~m}$, in some cases up to 400 $\mathrm{m})$ the depth increasing slightly, on average with an angle of $0.1^{\circ}$ and occasionally reaches $1^{\circ}$ (Fig. 3).

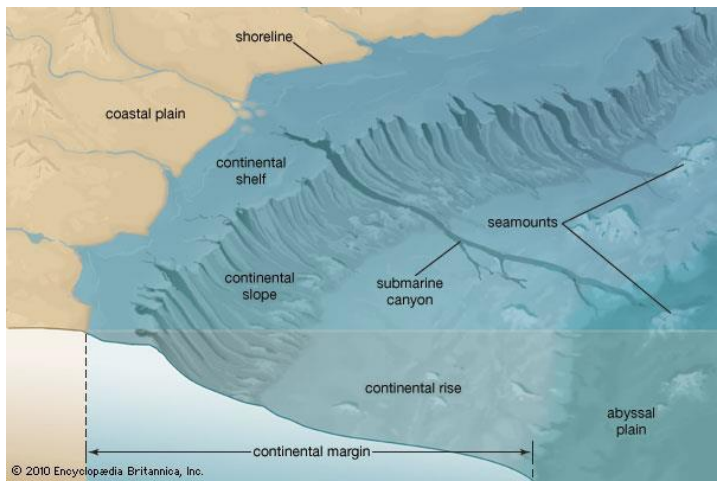

Figure 3 The main components and major submarine landforms of a continental margin) [4]

\subsection{Geodynamic processes}

On continental shelves, where the value of the slope gradient is higher, the deposition in large quantities of fine sediments can raise problems of slope stability. When combined with coarser sediments brought by rivers and streams from the mainland, their balance could become unstable. Water fills all the spaces and pores in the sediment and can act as a lubricant. An event such as an earthquake can trigger a mass of sediment. Sometimes, the own weight of the sediment can increase beyond the stability threshold, and the 
landslide can occur without the occurrence of such events.

From the investigations of the causes that led to the interruption, over time, of several submarine telecommunication cables, information was obtained about the geodynamic processes that affect the submarine sediments [5].

In areas close to the shore, the main dynamic processes are determined by waves and sea currents, as well as by the flow of sediment discharged by rivers. The magnitude of their actions depends on the local topography of the coast, the depth of the water and the climate pattern (precipitation, humidity, etc.). In areas with high seasonal rainfall and a soft soil structure (sand, soft sandstone, clay) erosion can be strong enough to turn large amounts of soil into sediments, which then reach the sea and form sediment deposits. This large amount of material transported over hundreds or thousands of years creates the largest accumulations of sediment on earth. Large sediment accumulations can lose their stability and begin to move along the slope at high speeds that can reach $19 \mathrm{~m} / \mathrm{s}$. The small amounts of sediment encountered at the ends of the canyon should not be neglected either, which in turn can start moving at speeds that can reach $5 \mathrm{~m} / \mathrm{s}$ over distances of hundreds of kilometres [5]. If electrical or telecommunication cables are installed in the direction of these movements, they may be broken or subjected to additional mechanical stress.

\subsection{Waves and sea currents}

Both types of movements can affect submarine cables by the forces developed by the action of water or by redistribution of sediments.

The action of the waves is stronger on the shore or in shallow waters and decreases with increasing depth. In general, the action of the waves stops at a depth of about $30 \mathrm{~m}$. Only exceptionally, during strong storms the action of the waves is felt more deeply. Coastal areas, especially sandy ones, are undergoing the most dramatic changes due to the action of waves. When cables in such areas are not buried deep enough, they can be brought to the surface (Fig. 4)

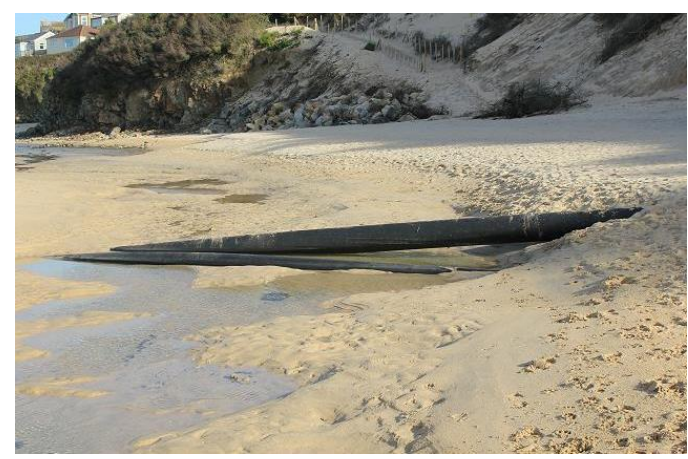

Figure 4 Cable exposure due to waves' action on a sandy beach in Great Britain [6]

\subsection{Temperature, salinity and corrosion}

The characteristics of sea water differ from one place to another due to climatic zones, inland water influences, biotic activity and its depth. The study of these characteristics contributes to the optimal choice of the materials from which the submarine cables are built.

The electric current passing through a conductor causes its temperature to rise. If the current becomes too high, the conductor reaches a critical temperature at which the insulation parts cannot work properly or may even begin to melt. Under normal operating conditions, the cable temperature must not reach these critical limits. Also, the ambient temperature plays an important role in maintaining the functional parameters in their optimal range. Because most cables are located in fairly cold regions, the lower temperature has a cooling effect on the cable, improving its efficiency.

The sea water temperature follows the general pattern of climatic zones with local influences caused by the movement of air masses from the land. As a general rule, the temperature decreases with depth (Fig.5) reaching $4^{\circ} \mathrm{C}$ at $1000 \mathrm{~m}$ depth (Fig.6) maintaining this temperature to the bottom of the sea.

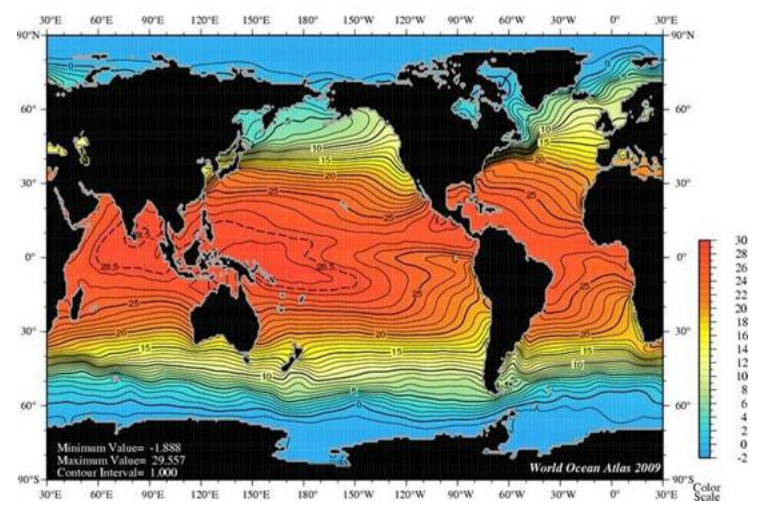

Figure 5 Annual temperature at the ocean's surface [7]

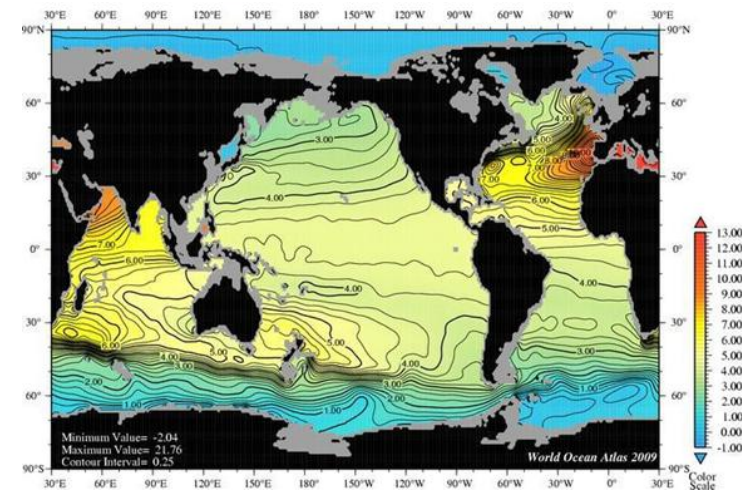

Figure 6 Annual temperature at $1000 \mathrm{~m}$ depth [7]

Salt water is a corrosive environment. Salt is present everywhere in seawater, in varying 
Installing submarine cables is a complex process. In concentrations. The average salinity in the planetary ocean is $33-36 \%$ with large variations.

In shallow and / or closed seas, located between the tropics (and not only), where strong evaporation takes place, the salinity of the waters can reach $37-40 \%$, as is the case of the Red Sea, the Mediterranean Sea, the Arabian Sea or the Atlantic, and Pacific in the tropics. A major tributary river can decrease the salinity of a sea or part of it, such as the Black Sea, the Baltic Sea, the North Sea, the South China Sea and the Bay of Bengal. Salinity is lower along the coasts and higher offshore. The North Sea has a salinity of 32-36\%o offshore and $15-25 \%$ close to shore.

Because salt has a higher specific gravity than water, salinity increases with depth. For these reasons, submarine cables must be protected against the corrosive effects of salt water. This issue needs to be taken seriously by the cable industry.

\section{INSTALLATION OF SUBMARINE CABLES IN THE OFFSHORE WIND INDUSTRY}

\subsection{Submarine cable handling limits}

Normally the process of installing a submarine cable consist in a static and a dynamic part. The static part is the one on the cable installation vessel (CLV) and the one installed on the seabed in stable environmental conditions, while the dynamic part is represented by the cable segment between the storage drums on the CLV and the area where the cable stabilizes on the seabed. The dynamic part is subject to loading due to ship movements and environmental factors. The seabed touchdown zone (TDZ), which is the area where the cable first touches the seabed, is essential for studying the possibilities of cable failure during installation. This area can be exposed to severe bending and axial compression, which can lead to local buckling inside the section that causes the cross section to unstable in torsion, global loop formation, or a combination of those that may finally result in capacity failure.

The current practice is to avoid compression at TDZ to eliminate any possibility of cable failure. Although it is not always clear how much composite submarine cables can be compressed before their integrity is compromised, cable manufacturers are often reluctant to allow significant compression of cables. This reduces the weather window for the installation operation, as the dynamic responses of the CLV, in particular the movements along the cable axis significantly affect the axial force applied to the cable during installation. A limited weather window leads to high installation costs. Therefore, it is of great interest to study different installation scenarios and to identify and make available to those who install submarine cables efficient methods of analysis. Thus, they can accurately monitor / analyse the operation of cable installation, in order to eliminate CLV waiting time. the planning phase, an analysis of this process must be carried out, taking into account factors such as cable properties, route characteristics, available installation equipment and the technical capabilities of the ship intended for installation (Fig.7) shows some of the most influential parameters in an installation operation:

- departure angle is the complimentary angle of the cable exit angle at the overboard chute of the CLV

- top tension is the tension applied to the cable using the onboard cable tensioners

- layback is the horizontal distance between the cable exit point from the CLV and the touch down point (TDP) on the seabed

- bending radius at TDP is the current radius of curvature of the cable and is one of the most important design parameters for cable integrity

- the cable tension on the seabed is the residual tension at TDP, representing another critical parameter for the cable life.

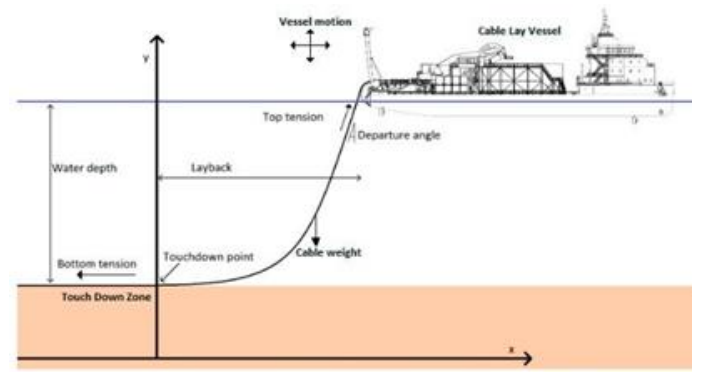

Figure 7 The most influential parameters in an installation operation [8]

\subsection{Submarine cable installation technique}

Submarine power cables can be installed in several methods, new techniques being constantly developed. However, the most common methods for installing submarine cables, depending on how the cable enters the water, are:

- S-lay- this is the most commonly used method. As can be seen in the figure 8 , for the installation of submarine cables a slide is used that guides the cable in the water. It will have a radius greater than or equal to the minimum bend radius (MBR) of the cable to be installed and has no obstructions for accessories or cable-mounted joints. Most offshore wind power cables are installed this way

- S-lay with stinger - this method is similar to the above but is used mainly in deep water and has the role of supporting the cable over a longer length

- J-lay - in this situation the cable will move through a vertical tensioner to keep the value of the MBR within limits, making this method have a good applicability in deeper waters. Another advantage of this method is the increased flexibility in the location of the tensioner, the cable can also be installed through the moonpool, thus reducing the effect of pitching and 

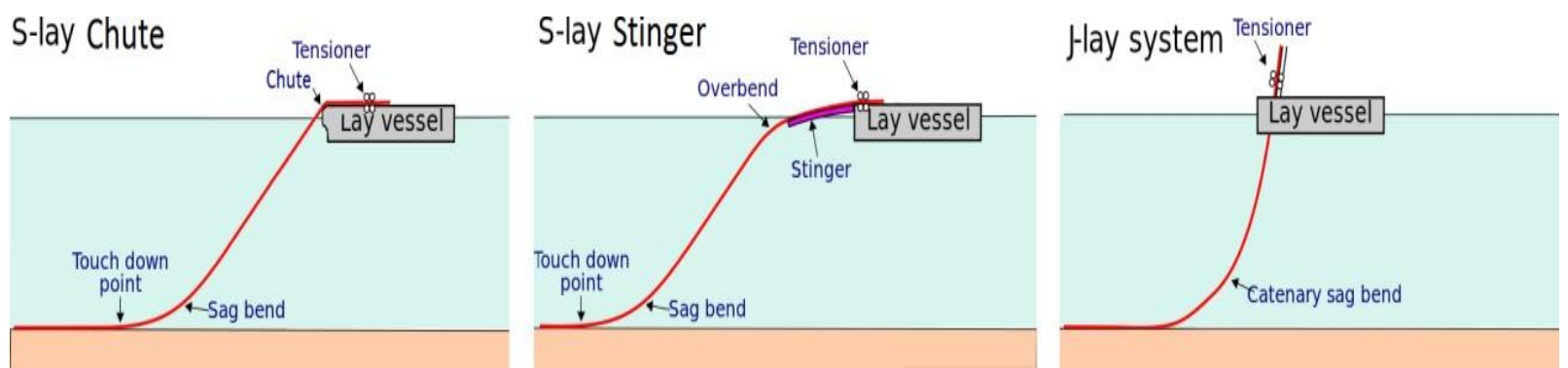

Figure 8 S-lay with Chute, S-lay with Stinger and J-lay [8]

\subsection{Installation of submarine cables in shallow water}

The installation of submarine cables in deep water is done with specialized ships and state-of-the-art equipment. Unfortunately, the installation and repair of submarine cables in shallow water remains a challenge, and it is necessary to develop new concepts to ensure increased efficiency and reduced environmental impact.

As I have seen in several projects in which I have been involved, for the connection to the shore of submarine cables, the installation used techniques, often lead to cable damage and increase the costs of these operations, having a negative impact on the environment. This leads to the decision to use various types of pontoons or barges, with various technical capabilities, with or without their own propulsion. Unfortunately, these installation methods involve the use of a large number of tugs and / or other equipment (fig.9 and fig.10).

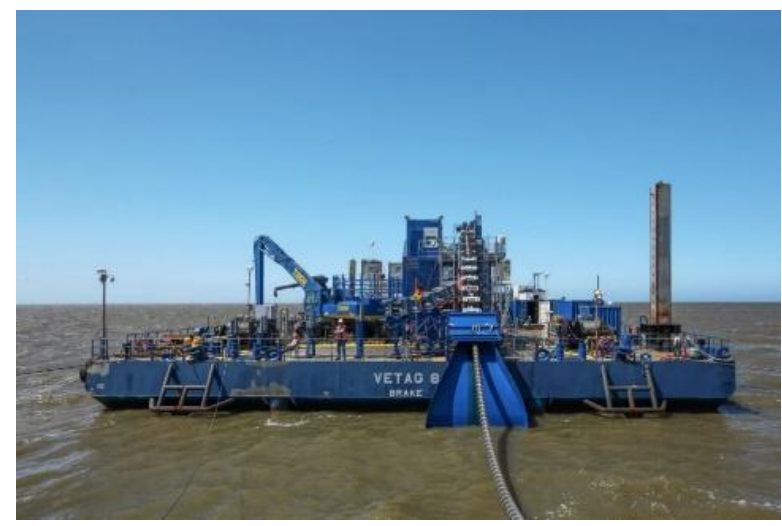

Figure 9 CLV VETAG 8 [9]

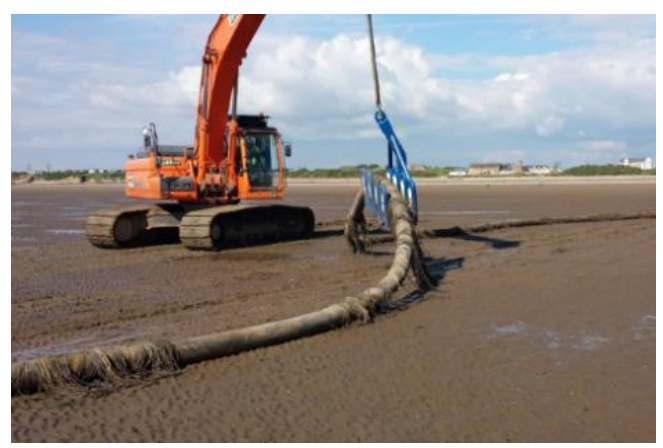

Figure 10 Crawler excavator into intertidal zone [9]

\section{VESSEL MOTION ANALYSIS}

A submarine cable suspended from the chute of an installation vessel will have a catenary shape due to its limited bending stiffness. The catenary shape together with the quadratic drag equations are important sources of non-linear cable response. This chapter explores the character of cable response based on quasi statics and drag. The obtained results will be the basis of the compression limit theory, which will be verified by a numerical analysis.

To study the behaviour and reaction of the cable to the movement of the ship we need a quasi-static analysis from which to obtain the following:

a. Catenary equation - a geometric catenary is the curve that a suspended cable forms under its own weight when it is supported at its ends. In order to simplify the analysis, it will be considered as an ideal situation that the cable material is continuously homogeneous and its bending stiffness and elastic elongation are equal to zero. These ideal conditions are generally acceptable for the installation of submarine cables. Elastic elongation is normally $\varepsilon \mathrm{c}<1 \%$ because high stresses are not desirable and material homogeneity and bending stiffness are also small factors compared to other values that occur during cable installation. [10]. The catenary shape is described by the hyperbolic cosine as in equation (1), its shape is 
defined by the catenary shape parameter - a. The complete derivation of the catenary

equation based on the force balance with zero bending moment in elements is presented below, the coordinate system in figure 11 is used to obtain the necessary equations that will define the catenary shape.

$$
=a \cosh \left(\frac{x}{a}\right)=\frac{a\left(e^{\frac{x}{a}}+e^{-\frac{x}{a}}\right)}{2}
$$

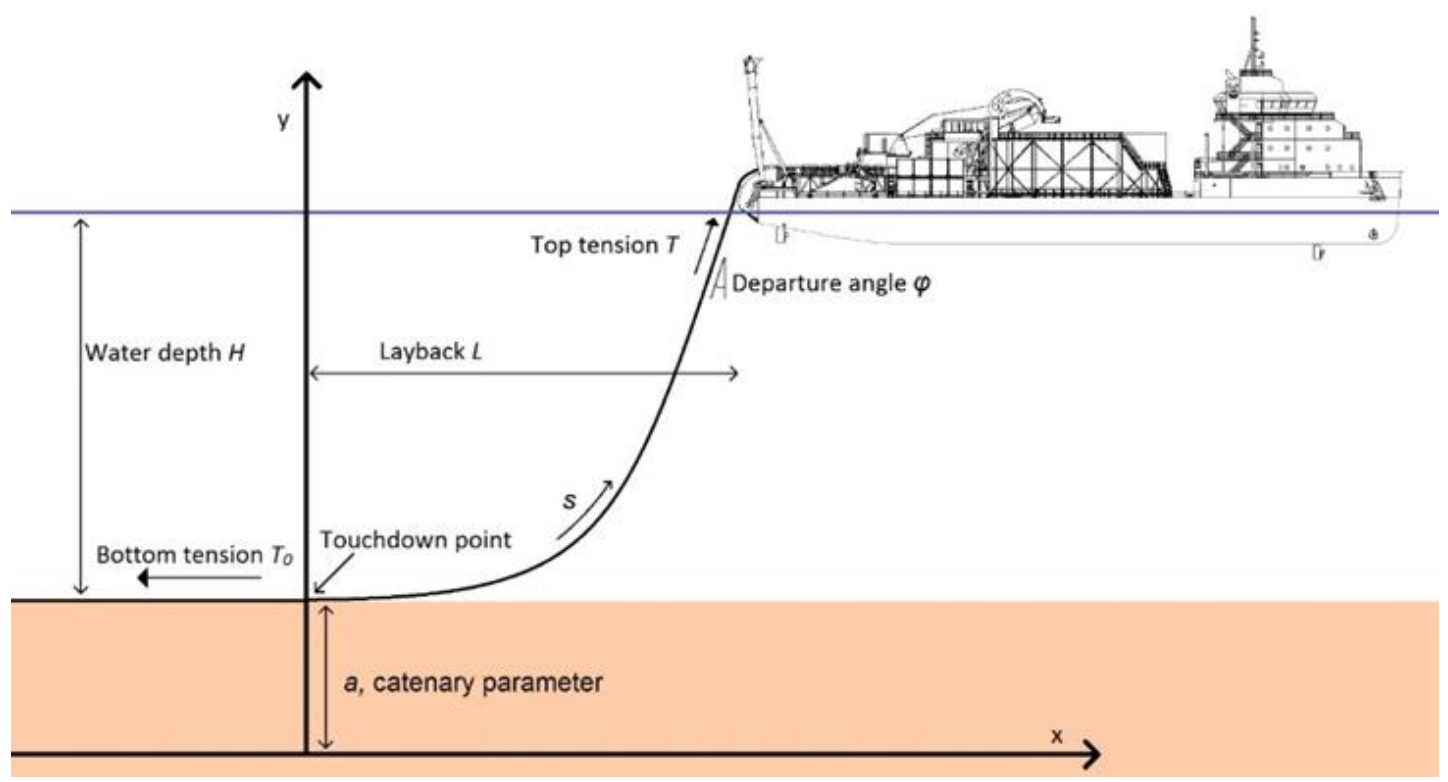

Figure 11 Catenary reference system [8]

The vertical force equilibrium is obtained by substituting $\lambda \mathrm{g}$ as the submerged weight of the cable

$$
T \sin (\varphi)=\lambda g s
$$

Dividing these equations (2\&3) will obtain:

$$
\frac{\mathrm{dy}}{\mathrm{dx}}=\tan (\varphi)=\frac{\lambda \mathrm{gs}}{\mathrm{T}_{0}}
$$

Here "a" is defined as the catenary shape parameter:

$$
\frac{d y}{d x}=\frac{s}{a} \text { were " } a "=\frac{T_{0}}{\lambda g}
$$

The formula for arc length is:

$$
\frac{d s}{d x}=\sqrt{\left(\frac{d y}{d x}\right)^{2}+1}=\frac{\sqrt{a^{2}+s^{2}}}{a}
$$

Which allows:
In the stationary regime, there must be an equilibrium of forces. The sum of the horizontal forces gives us:

$$
\operatorname{Tcos}(\varphi)=\mathrm{T}_{0}
$$

$$
\frac{d y}{d s}=\frac{d y}{d x} \frac{d x}{d s}=\frac{s}{a} \frac{a}{\sqrt{a^{2}}+s^{2}}=\frac{s}{\sqrt{a^{2}+s^{2}}}
$$

This differential equation can be integrated to:

$$
y=\sqrt{a^{2}+s^{2}}+\beta
$$

For which $\beta$ can be set to 0 by shifting the origin of the $\mathrm{x}$-axis and (6) is integrated with respect to $\mathrm{s}$, to obtain:

$$
x=a \sinh \left(\frac{s}{a}\right)+a
$$

Where again, $\alpha$ can be set to 0 by shifting the $y$ axis, obtaining:

$$
x=a \sinh \left(\frac{s}{a}\right), s=a \sinh \left(\frac{x}{a}\right)
$$

Combining Equation (9) and (10) will be obtain: 


$$
F_{g}=m_{s} g
$$

$$
y=\operatorname{acosh}\left(\frac{x}{a}\right)
$$

The catenary is now expressed by the hyperbolic parameter of the cosine and the catenary form "a".

b. Catenary effects - when the chute of the vessel moves in negative surge or heave direction, slackness is obtained in the cable. With enough time, the cable will sink towards the bottom. The tension will decrease, the TDP will move closer to the vessel and the balance of forces is restored.

c. Free fall velocity of the cable - when a segment of cable is horizontally placed in water and let loose, an equilibrium will be formed where the gravitational pull cancels out with the hydrodynamic drag and buoyancy. For this equilibrium, it is assumed that the cable does not rotate and moves through the fluid at right angles to its longitudinal axis.

The vertical force equilibrium demands:

$$
F=F_{d}-F_{g}=0
$$

The drag force is equal to:

$$
F_{d}=\frac{1}{2} \rho_{w} v_{r}^{2} C_{d} D
$$

The gravitational force is equal to:

Table 1 Parameters for cable velocity calculation

\begin{tabular}{|c|c|c|c|}
\hline Symbol & Variable & Value & Unit \\
\hline $\mathrm{m}_{\mathrm{s}}$ & submerged weight & 15.87 & $\mathrm{~kg} / \mathrm{m}$ \\
\hline $\mathrm{g}$ & gravity acceleration & 9.81 & $\mathrm{~m} / \mathrm{s}^{2}$ \\
\hline $\mathrm{D}$ & cable diameter & 0.121 & $\mathrm{~m}$ \\
\hline$\rho_{\mathrm{w}}$ & seawater density & 1025 & $\mathrm{~kg} / \mathrm{m}^{3}$ \\
\hline$\mu$ & kinematic viscosity $\left(4^{\circ} \mathrm{C}\right)$ & 0.00467 & $\mathrm{Ns} / \mathrm{m}^{2}$ \\
\hline$C_{d}$ & drag coefficient & 1.143 & - \\
\hline$V_{r}$ & velocity relative to water & 1.48 & $\mathrm{~m} / \mathrm{s}$ \\
\hline
\end{tabular}

From the calculations it is concluded that the cable model cannot fall faster through the water in lateral direction than $1.48 \mathrm{~m} / \mathrm{s}$. Due to the catenary effect a
Note that the submerged weight is used and therefore the buoyancy is already incorporated.

The normal flow drag coefficient for circular cylinders is dependent on the Reynolds number and surface finish. For the model cable, with a surface roughness of $10^{\wedge}-2$ the drag coefficients profile is shown in figure 12 .

The Reynolds number can be calculated as:

$$
R_{e}=\frac{\rho_{w} v_{r} D}{\mu}
$$

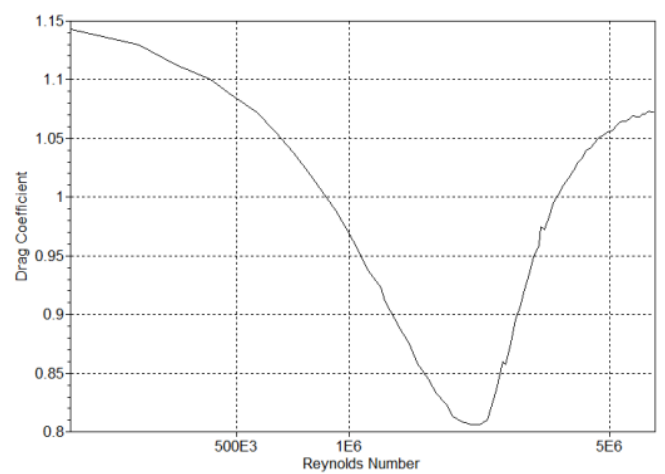

Figure 12 Drag coefficients of model cable

Iteration of the equations: $12-14$ results in a terminal velocity of $1.48 \mathrm{~m} / \mathrm{s}$ at a Reynolds number of $3.9 * 104$. The used parameters are listed in table 1 .

small excitation at the chute will lead to larger lateral excursions along the sag-bend. The same principle works for velocities. A small velocity of the chute in the axial 
direction of the cable, will lead to larger lateral velocities needed to maintain the catenary.

c. Tension loss and compression - when there is a loss of tension in the cable it will sink to the bottom of the sea. Due to the large lateral drag component and limited submerged weight, a significant portion of the cable weight will be affected by the drag. In other words,

when the cable falls through the water, the drag will impose a tension loss along the cable.

If the excitation of the cable is fast enough, the cable is no longer able to follow the catenary shape due to drag forces and all tension can be lost. The cable will move to the bottom with the lateral velocities governed by drag and the axial velocities governed by both inertia and the shape of the falling cable. When the free-falling cable segments hit the bottom with a certain velocity, their momentum will create compression in the cable which is undesirable.

The shape of the falling cable depends on the drag forces, which in turn depend on the velocity and orientation of the cable segments. Therefore, it is impossible to find an analytical expression for the cable under (partial)free fall and compression. Therefore, numerical time domain analysis is required to determine the velocity leading to cable compression.

Effects of TDP movement - as demonstrated above, the displacement of the displacement of the touch down point will be a number of times larger than the excursion of the cable at the chute (TDP). For a relatively low axial velocity, the TDP will have to move at a significant speed to maintain the catenary shape. This may be limited by the transverse wave velocity of the cable.

For a simplified analysis, the transverse wave velocity for a disturbance in a cable without stiffness is represented in equation (16).

$$
v_{t}=\sqrt{\frac{T_{0}}{m}}
$$

\section{ENVIRONMENTAL IMPACT OF SUBMARINE CABLE INSTALLATION}

Submarine cables, like any other external element inserted in the water or on the seabed, can cause disturbances to life and the marine environment. The magnitude of the disturbances refers to the way the cable interacts with the environment: positioned on the seabed or buried in the seabed. In addition to the presence of the cable itself, other influences could be considered, such as induced magnetism, noise, thermal radiation or the chemical and physical interaction between seawater, sediment and the insulation layer of the cable. The cable route can pass through protected areas or sensitive natural environments. The procedure for obtaining permits for the installation of a submarine cable includes an environmental impact assessment (EIA).
A formal EIA usually has at least the following components:

- description of the proposed operation;

- description of the receiving environment (covering all relevant physical, geological factors, biological and anthropogenic / socio-economic); environment;

assessment of potential effects on the

- assessment of mitigation measures necessary to reduce any effects to an environmentally acceptable level;

- assessment of any monitoring measures needed to ensure that the extent of an effect is maintained at an acceptable level.

\subsection{Cables installed on the seabed}

Physical interactions take place on the cables installed on the seabed due to the actions of natural or human factors.

Any interaction of cables with seabed habitats can be assessed by monitoring the biota before and after cable installation [11] or, in the case of installed cables, by comparing the biota in places near and far from a cable [12]. In addition, there are reports of epifauna and epiflora living on cables (Fig.13).

In general, those studies show that the presence of cables has no impact or if it has this impact has minor effects on the resident biota.

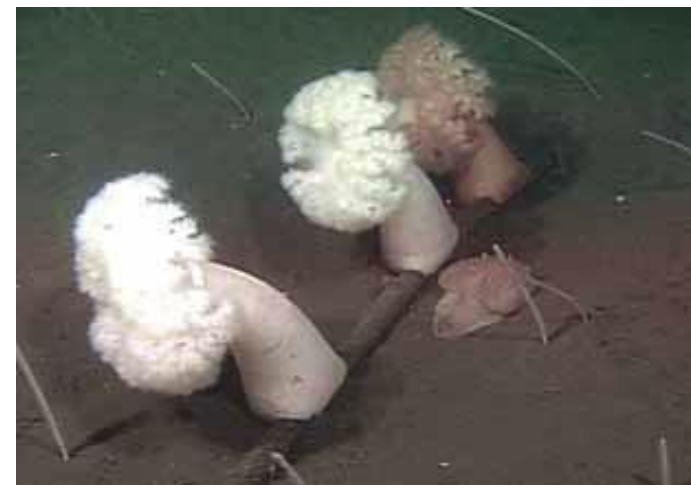

Figure 13 The exposed ATOC/Pioneer Seamount cable with attached anemones [13]

\subsection{Cables buried into the seabed}

Installing cables by burying them at the bottom of the sea can disrupt the marine environment. Compared to other offshore activities, such as bottom trawling, ship anchoring and dredging operations, cable burial operations are limited in time and are a non-repetitive operation, unless a cable needs to be repaired.

Decommissioning and recovery of a buried cable can also lead to disturbances in the marine environment, but again they are of limited and relatively rare 
magnitude, taking into account the projected lifespan of a submarine cable (20-25 years).

\section{CONCLUSIONS}

Ship and cable dynamics are considered uncoupled. The effect that the cable has on the ship's movements is negligible

There is a maximum value of compression that can occur for a certain cable configuration. This depends on the configuration of the catenary and the mass of the cable

With an adequate safety margin, it is possible to estimate the cable compression due to ship movements when installing cables in shallower water.

In terms of the frequency and relatively short duration of submarine cable installation operations, in a small strip of up to $8 \mathrm{~m}$, the disturbances and impact caused by these operations are considered minor as they are preferred over trawling and dredging operations, which are repetitive and more extensive (for example, a single bottom trawl can be tens of meters wide, can sweep substantial areas of the seabed in a single operation and is likely to be repeated over. A single impact, such as cable burial operations, is preferred to continuous, multiple, or recurring impacts.[14]

Uninstallation of cables - as the cables reach the end of their life or due to technological advances, their removal from the seabed may be considered. In the case of a buried cable, removing it can lead to disturbance to marine life. In this context, the cable may support an epifauna that would be lost during a recovery procedure, which is why it may be considered prudent to leave the cable in place to preserve the epifauna.

\section{REFERENCES}

[1] NOAA, 2005. Final Environmental Analysis of Remediation Alternatives for the Pacific Crossing-1 North and East Submarine Fiber-optic Cables in the Olympic Coast National marine Sanctuary. National Oceanographic and Atmospheric Administration.
[2] Mircea A., Philip M., HVDC Submarine Power Cables in the Word, JRC technical report from 2015.

[3] https://www.ngdc.noaa.gov/mgg/image/sedthick9.jpg

[4] https://www.britannica.com/science/continental$\underline{\text { margin }}$

[5] Carter L., Gavey R., Talling P.J. and Liu J.T., 2014, Insights into submarine geohazards from breaks in subsea telecommunication cables, Oceanography.

[6] https://www.aphotomarine.com/geology_sand erosion_wave hub_cable cornwall.html

[7] NOAA, 2006. Hurricanes. National Hurricane Center.

[8] DNV GL. Guideline for installation of rigid and flexible pipelines, umbilicals and subsea power cables Limit state criteria, 2015.

[9] West of Duddon Sands - project , https://westofduddonsands.co.uk/about-the-project

[10] Kurt J. P., Empirical Factors in the Prediction of Helically Armoured Cable Axial Stiffness. s.l.: ASME, 1984.

[11] Andrulewicz E., Napierska D. and Otremba Z., 2003. The environmental effects of the installation and functioning of the submarine SwePol Link HVDC transmission line: A case study of the Polish Marine Area of the Baltic Sea, Journal of Sea Research 49.

[12] Kogan I., Paull C., Kuhnz L., Burton E., Von Thun S., Greene H.G. and Barry J., 2006. ATOC/Pioneer Seamount cable after 8 years on the seafloor: Observations, environmental impact, Continental Shelf Research.

[13] Levings C.D. and McDaniel N.G., 1974. A unique collection of baseline biological data: Benthic invertebrates from an underwater cable across the Strait of Georgia. Fisheries Research Board of Canada, Technical Report 441.

[15] NOAA, 2009. NOAA Report: Four Fish Stocks Declared Fully Rebuilt. 